\title{
International Nuclear Engineering Research Initiative Project at INL, ANL, and KAERI
}

C.H. Oh

C. Davis

S. Sherman

R. Vilim

Y. Lee

W. Lee

April 2006

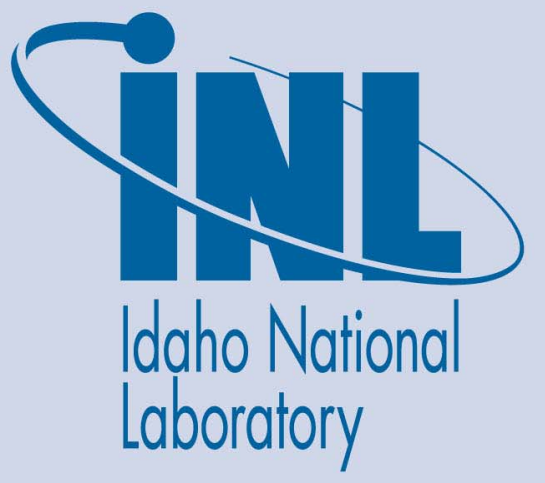

The INL is a U.S. Department of Energy National Laboratory operated by Battelle Energy Alliance 


\title{
International Nuclear Engineering Research Initiative Project at INL, ANL and KAERI
}

\author{
C.H. Oh \\ C. Davis
}

S. Sherman

R. Vilim

Y. Lee

W. Lee

April 2006

Idaho National Laboratory
Idaho Falls, Idaho 83415

Prepared for the

U.S. Department of Energy

Office of Nuclear Energy

Under DOE Idaho Operations Office

Contract DE-AC07-05ID14517 


\section{International Nuclear Engineering Research Initiative Project at INL, ANL, and KAERI}

C.H. Oh, C. Davis, S. Sherman at INL, R. Vilim at ANL, and Y. Lee, W. Lee at KAERI Phone: (208) 526-7716 Email: Chang.Oh@,inl.gov

As part of I-NERI program, two US laboratories, INL and ANL, and one laboratory, KAERI, are involved in development of HyPEP, a hydrogen production plant efficiency calculation computer code.

The Department of Energy envisions the next generation very high-temperature gascooled reactor (VHTR) as a single-purpose or dual-purpose facility that produces hydrogen and electricity. The Ministry of Science and Technology (MOST) of the Republic of Korea also selected VHTR for the Nuclear Hydrogen Development and Demonstration (NHDD) Project. This collaborative work will address the evaluation of hydrogen and electricity production cycle efficiencies for such systems as the VHTR and NHDD, and the optimization of system configurations.

This project will select a reference design that deals with the primary coolant system, the secondary coolant system, the intermediate heat transfer loop, the hydrogen production plant and all requirements. Calculations are based on methods defined for the plant efficiency, HyPEP overall numerical schemes, partial load and operating constraints. Both thermochemical and HTE processes will be included in the complex system.

Optimization of such complex systems as VHTR and NHDD will require a large number of calculations involving a large number of operating parameter variations and many different system configurations. The research will produce (a) the HyPEP which is specifically designed to be an easy-to-use and fast running tool for the hydrogen and electricity production evaluation with flexible system layout, (b) thermal hydraulic calculations using reference design, (c) verification and validation of numerical tools used in this study, (d) transient analyses during start-up operation and off-normal operation. This project will also produce preliminary cost estimates of the major components.

In order to optimize the designs of such plant systems as VHTR (Figure 1) and NHDD (Figure 2), it is necessary to be able to evaluate the operating parameters and production efficiencies of various design layouts. This project was funded for three-year and as a final product, we will produce HyPEP computer code along with steady-state and transient analyses on NHDD. 


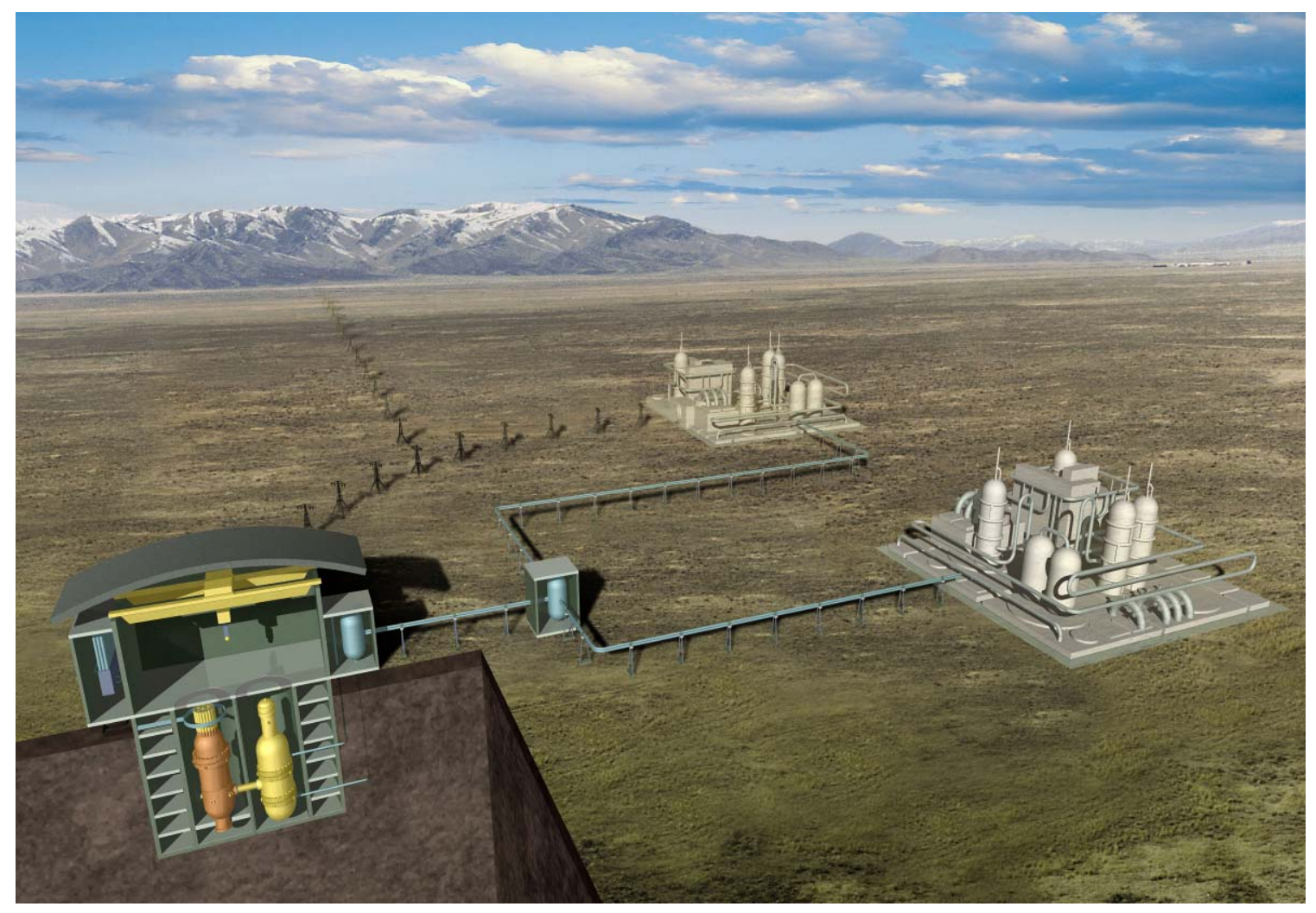

Figure 1. Potential Layout of VHTR for Hydrogen Production.

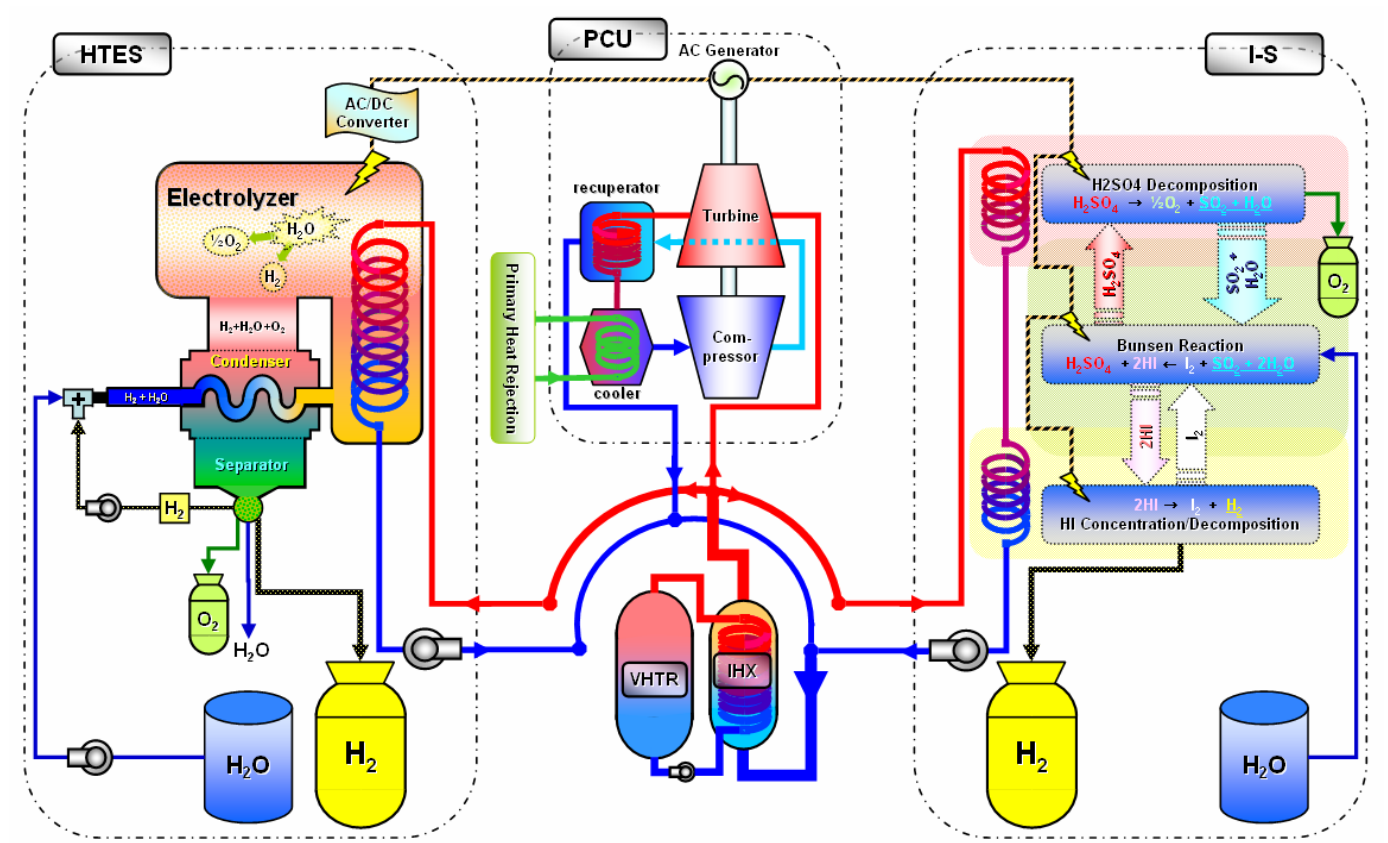

Figure 2. Potential Layout of Proposed NHDD Plant. 
